\title{
Determination of Polycyclic Aromatic Hydrocarbons in Tea Infusions Samples by High Performance Liquid Chromatography with Fluorimetric Detection
}

\author{
Anna Maria Girelli, ${ }^{1}$ Azzurra Apriceno, ${ }^{1}$ Anna maria Tarola, ${ }^{2}$ and Francesca Tortora ${ }^{1}$ \\ ${ }^{1}$ Department of Chemistry, Sapienza University of Rome, P.le A.Moro 5, 00185 Rome, Italy \\ ${ }^{2}$ Department of Management, Laboratory of Commodity Science, Sapienza University of Rome, Via Castro Laurenziano 9 , \\ 00161 Rome, Italy
}

Correspondence should be addressed to Anna Maria Girelli; annamaria.girelli@uniromal.it

Received 13 July 2016; Accepted 19 October 2016; Published 11 January 2017

Academic Editor: Elena González-Fandos

Copyright (C) 2017 Anna Maria Girelli et al. This is an open access article distributed under the Creative Commons Attribution License, which permits unrestricted use, distribution, and reproduction in any medium, provided the original work is properly cited.

\begin{abstract}
This study focuses on the contamination of 15 polycyclic aromatic hydrocarbons (PAHs), recommended by the US Environmental Protection Agency, in 10 tea brands distributed in Italy. Analyses were carried out with a procedure based on saponification, liquidliquid extraction, and PAHs determination by high performance liquid chromatography with fluorescence detector. A comparison with ultrasonic extraction in bath water was also reported. Contamination is expressed as the sum of analyzed PAHs and ranged between 347 and $4120 \mathrm{ng} / \mathrm{L}$ with a mean value of $1675 \mathrm{ng} / \mathrm{L}$. PAHs with 3-4 rings were dominant with a contribution of $92 \%$, while $7 \%$ and $1 \%$ were found for PAHs with 5 and 6 rings, respectively. Moreover, data revealed that three samples exceeded the EU 2008 criteria established for drinking water in which the sum of benzo[k]fluoranthene, benzo[b]fluoranthene, benzo[g,h,i]perylene, and indeno[1,2,3-cd]pyrene is considered $(<100 \mathrm{ng} / \mathrm{L})$ and two samples exceeded the $10 \mathrm{ng} / \mathrm{L}$ level allowed for benzo[a]pyrene.
\end{abstract}

\section{Introduction}

Tea is the most popular beverage in the world, second only to water, with per capita world Yang wide consumption approximately of $40 \mathrm{~L} / \mathrm{y}$ (consumption of $<120 \mathrm{~mL}$ brewed tea per day) [1]. The health effects of tea leaves have been widely studied. There are a lot of scientific reports indicating that tea consumption might have health promoting properties like cholesterol reduction, antioxidant features, and protection against cardiovascular disease $[2,3]$. Moreover, examination of different contaminants residues in tea leaves (pesticides, heavy metals, and fluoride) began to be required since some environmental (atmospheric deposition and soil factors) and anthropic (use of organic fertilizers, production steps, and irrigation with polluted water) factors could contaminate tea. PAHs, which occur ubiquitously and are generated by pyrolysis of organic material, have been actually less investigated. Among 660 polycyclic aromatic hydrocarbons some compounds show carcinogenic properties [4]. Benzo[a]pyrene is well known as carcinogenic PAH and it has been used as a leading substance until now [5]. However, the European Food Safety Authority reported that benzo[a]pyrene is not a suitable marker for the occurrence of PAHs in food and a system of four or eight specific substances should be preferred [5]. As a consequence, Commission Regulation Number 835/2011 amended Regulation (EC) Number 1881/2006 in order to set maximum levels for the sum of four polycyclic aromatic hydrocarbons (benzo[a]pyrene, benzo[a]anthracene, benzo[b]fluoranthene, and chrysene).

Plants can adsorb polycyclic aromatic hydrocarbons especially from air [6]. Tea leaves in particular possess a high surface area and consequently can easily reach high level of PAHs accumulation. Moreover, the manufacturing process of tea leaves, like drying step which uses combustion gases from burning wood, oil, or coal, may be another source of PAHs especially in black teas [7]. These factors can cause human exposure to polycyclic aromatic hydrocarbons through tea consumption with possible threat for human health. So far, 
any maximum level of PAHs in samples of tea has not been established.

However, several studies concerning the analysis in dried black tea of the PAHs recommended by the US Environmental Protection Agency [8] have been made [6, 7, 914]. Literature data show that the contamination of black tea greatly varies in function of the tea origin. So in dried black tea supplied from German supermarkets, as reported by Ziegenhals et al. [6], PAHs content ranged between 14 and $89 \mu \mathrm{g} / \mathrm{Kg}$ while, for those supplied in China, and mean values of $9650 \mu \mathrm{g} / \mathrm{Kg}, 8800 \mu \mathrm{g} / \mathrm{Kg}$, and $1162 \mu \mathrm{g} / \mathrm{Kg}$ are reported by Lin and Zhu [7], Lin et al. [11], and Fiedler et al. [9], respectively.

Few researches have focused on the determination of PAHs into black tea infusions [15-17] but, in this case, it is hard to compare data since a different number of PAHs are taken into account. However, Ciemniak and Mocek [18] and Lin et al. [11] reported that the percentages and distribution of total polycyclic aromatic hydrocarbons into drink are very lower than those in dry teas because of their low solubility in water. Analyses of PAHs are generally performed by high performance liquid chromatography (HPLC) coupled with UV-visible or fluorimetric detector (FLD) and gas chromatography (GC) with mass spectrophotometer (MS). Díaz-Moroles et al. [19] report that although both approaches are adequate for the analysis of PAHs in water, a higher sensitivity and a lower relative standard deviation $\%$ value were achieved using HPLC-FLD. These considerations are confirmed by Filipkowska et al. [20], too.

For the above-mentioned reason, in this study, HPLC/ FLD was chosen. Contamination of PAHs was studied in black tea since it is the most consumed quality in the world and it can be more easily contaminated by manufacturing process. To the best of our knowledge, no previous study was done on black tea supplied in Italian market. The research was performed on tea infusion in order to evaluate the real potential risk associated with tea beverage consumption. In addition a comparison between two different methodologies as sonication in ultrasonic bath and saponification followed by liquid-liquid extraction is reported.

\section{Materials and Methods}

2.1. Chemicals. A certified solution of 16 standard polycyclic aromatic hydrocarbons (naphthalene; acenaphthylene; acenaphthene; fluorene; phenanthrene; anthracene; fluoranthene; pyrene; benz[a] anthracene; chrysene; benzo[k] fluoranthene; benzo[b]fluoranthene; benzo[a]pyrene; indeno[1, 2,3-cd]pyrene; dibenz[a,h] anthracene; and benzo[g,h,i]perylene) with $10 \mathrm{mg} / \mathrm{L}$ concentration of each compound was purchased from Supelco, Milan, Italy.

All solvents (water, acetonitrile, and cyclohexane) used for sample preparation and analysis were HPLC grade from Sigma-Aldrich (Milan, Italy). Sodium hydroxide RPH employed for saponification was from Sigma-Aldrich (Milan, Italy).
2.2. Standard Preparation. Working solution in the range 1 to $50 \mu \mathrm{g} / \mathrm{L}$ was obtained by dilution in acetonitrile and stored in amber glass vials at $4^{\circ} \mathrm{C}$ until the use.

2.3. Sample Collection and Preparation. A total of 10 brands of black teas were purchased from Italian market. To prepare the infusion 1.5-2 g of the tea sample was submerged in $100 \mathrm{~mL}$ boiling ultrapure water. Then the flask was placed in water bath with the temperature maintained at $95^{\circ} \mathrm{C}$ for $10 \mathrm{~min}$. Afterwards, the water phase was decanted and cooled to about $30^{\circ} \mathrm{C}$.

2.4. Extraction Methods. Two different approaches have been used for the extractions. In first ultrasonic bath (US) has been employed since it has the ability to easily mix two or more immiscible liquid phases and promote, thanks to the cavitational forces generated, the mass transfer of the analyte between the liquid phases. In the second mode, a classic liquid-liquid extraction by shaking is performed after a saponification process.

2.4.1. Mode 1: Ultrasonic Extraction. Twelve $\mathrm{mL}$ of tea infuse was extracted by ultrasonication in ultrasonic bath with $4 \mathrm{~mL}$ of cyclohexane for $30 \mathrm{~min}$. Subsequently $3 \mathrm{~mL}$ of the extractant solvent was evaporated to dryness under nitrogen to remove cyclohexane. The residue was then recovered with $100 \mu \mathrm{L}$ of acetonitrile.

2.4.2. Mode 2: Saponification Followed by Liquid-Liquid Extraction Method. Four $\mathrm{mL}$ of tea infusion and $4 \mathrm{~mL}$ of ethanolic $\mathrm{NaOH} 0.6 \mathrm{M}$ were heated at $60^{\circ} \mathrm{C}$ for $30 \mathrm{~min}$. After cooling an extraction step was carried out stirring with $2 \mathrm{~mL}$ of cyclohexane for $5 \mathrm{~min}$. The supernatant layer was then recovered and transferred in a vial. The extraction step was made twice. Then $3 \mathrm{~mL}$ of the combined cyclohexane extracts was taken and evaporated to dryness under nitrogen. The residue was then recovered with $100 \mu \mathrm{L}$ of acetonitrile.

2.5. Chromatographic Polycyclic Aromatic Hydrocarbons Determination. The HPLC analysis was conducted, for both methods, by injecting $20 \mu \mathrm{L}$ of the organic extract into the chromatographic system and polycyclic aromatic hydrocarbons concentrations were determined with external calibration method. The chromatographic system consisted of a liquid chromatographic module (Jasco PU1580), 7125 injector (Rheodyne, Cotati, CA, USA) with a $20 \mu \mathrm{L}$ sample loop, a 110 series fluorescence detector (Agilent), and a Hewlett-Packard chemstation integrator. Separation of polycyclic aromatic hydrocarbons was achieved by a column C-18 $(150 \times 4.6 \mathrm{~mm}$ I.D.) (particle size $5 \mu \mathrm{m})$ (ProSphere 300, Alltech) with a gradient elution program using solvent $\mathrm{A}$ $\left(\mathrm{H}_{2} \mathrm{O}: \mathrm{CH}_{3} \mathrm{CN}=99: 1 \mathrm{v}: \mathrm{v}\right)$ and solvent $\mathrm{B}\left(\mathrm{CH}_{3} \mathrm{CN}: \mathrm{H}_{2} \mathrm{O}=\right.$ $99: 1 \mathrm{v}: \mathrm{v})$. The gradient elution was programmed as follows: $40 \% \mathrm{~B}$ to $50 \%$ B linearly $(0-20 \mathrm{~min}), 50 \% \mathrm{~B}$ to $100 \% \mathrm{~B}$ (20-37 $\mathrm{min}), 100 \% \mathrm{~B}(37-42 \mathrm{~min})$, and $100 \% \mathrm{~B}$ to $40 \% \mathrm{~B}$ (42-45 $\mathrm{min})$. The flow rate was set at $0.9 \mathrm{~mL} / \mathrm{min}$, at room temperature. Under these conditions, 15 polycyclic aromatic hydrocarbons could be separated satisfactorily within $45 \mathrm{~min}$ 


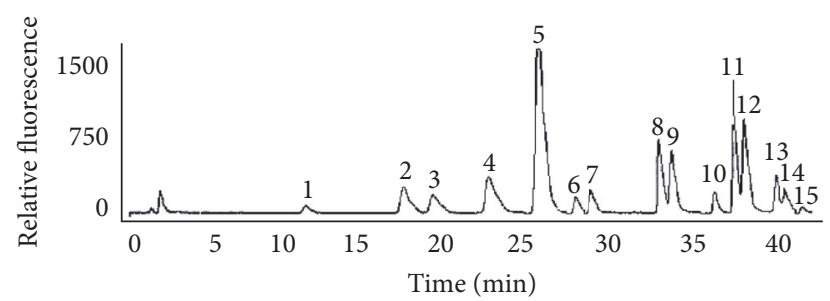

Figure 1: Chromatogram of a standard polycyclic aromatic hydrocarbons solution: 1: naphthalene, 2: acenaphtene, 3: fluorene, 4: phenanthrene, 5: anthracene, 6: fluoranthene, 7: pyrene, 8: benz [a]anthracene, 9: chrysene, 10: benzo[b]fluoranthene, 11: benzo[k] fluoranthene, 12: benzo[a]pyrene, 13: dibenz[a,h]anthracene, 14: benzo[ghi]perylene, and 15: indeno[1,2,3-cd]pyrene. Chromatographic conditions as reported in Section 2.5.

(Figure 1). Acenaphthylene has not been examined since it is a compound poorly or not fluorescent. The detection wavelength program to determine individual polycyclic aromatic hydrocarbons is previously reported [21].

2.5.1. Recoveries. For recovery studies, $12 \mathrm{~mL}$ of a black tea infusion was spiked with 10 and $20 \mathrm{ng}$ of each polycyclic aromatic hydrocarbons standard solution for ultrasonic extraction method while 1 and $2 \mathrm{ng}$ were added to $4 \mathrm{~mL}$ of tea infusion for saponification method. Recoveries on 5 replicate samples were determined as the difference between the polycyclic aromatic hydrocarbons values in the fortified sample and those of the same infusion without any addition, with respect to polycyclic aromatic hydrocarbons added amount. Results are reported as percent recovery.

The blank was subtracted from all the analysis results to obtain the real contribution of tea.

\section{Results}

3.1. Optimization of PAHs Determination with Ultrasonic Extraction Method. In order to optimize PAHs extraction from tea infusion by ultrasonic device, it was necessary to investigate the ultrasonication time effect, the infuse/cyclohexane volumes ratio, and the optimal number of treatments with the extractant solvent (cyclohexane).

It is well known that the ultrasonication time in effect might have influence on extraction efficiency because it affects both emulsification and mass transfer process. To confirm its influence, a study at three different ultrasonication times of 20,30, and $40 \mathrm{~min}$ for PAHs extractions on tea fortified with $5 \mathrm{ng}$ of polycyclic aromatic hydrocarbons was carried out. In Figure 2, as example, results of benzo[a]pyrene, benzo[g,h,i]perylene, indeno[1,2,3-cd]pyrene, benzo[b]fluoranthene, and benzo[k]fluoranthene are reported, the most relevant polycyclic aromatic hydrocarbons in drinking water. The maximum extraction yield is achieved at $30 \mathrm{~min}$ for all PAHs. The increase of extraction percentage from $20 \mathrm{~min}(70-80 \%)$ to $30 \mathrm{~min}(100 \%)$, according to Falleh et al. [22], could be due to the fact that bubbles tend to grow with time until they reach a size sufficient to cause disruption and consequently to enhance extraction yield.

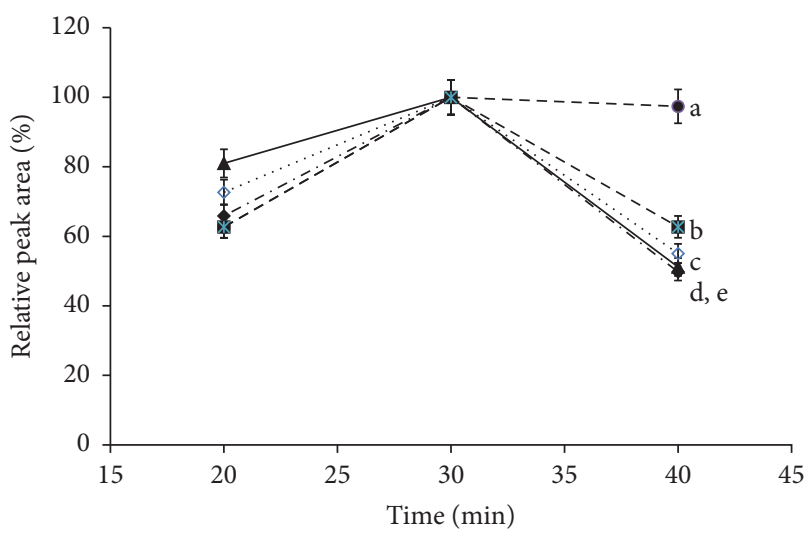

FIgURE 2: Effect of ultrasonic time on some polycyclic aromatic hydrocarbons release from tea infusion to organic phase. a: benzo[ghi]perylene; b: indeno[1,2,3-cd]pyrene; c: benzo[b]fluoranthene; d: benzo[a]pyrene; e: benzo[k]fluoranthene.

After 30 min the yield decreases (40-50\%) probably due to the increase of temperature in bulk solution up to a value in which the performance of the ultrasonic treatment can be deteriorated. This can be ascribed to a lower cavitation efficiency caused by the decrease of liquid density for the increased temperature [23]. In fact as solvent temperature rises, its vapor pressure increases and so more solvent vapor fills the cavitation bubbles, which then tend to collapse less violently and the sonication effects are less intense than expected.

However, it was established to fix the ultrasonication time to $20 \mathrm{~min}$ in order to have the best compromise between the time of analysis and the \% extraction.

In order to optimize the number of infuse treatments with cyclohexane, two different procedures were evaluated. A tea sample spiked with $5 \mathrm{ng}$ of each polycyclic aromatic hydrocarbons was extracted once for $20 \mathrm{~min}$ in the first approach and twice $(2 \times 10 \mathrm{~min})$ in the latter. In both cases $1: 1$ and $3: 1$ volumes ratios of aqueous sample to organic solvent (cyclohexane) were employed. The obtained data showed that when twice extractions were performed, for both volume ratios, total polycyclic aromatic hydrocarbons content was $53 \%$ and $48 \%$, respectively, lower than that of a single extraction. This result can be attributed both to a large affinity of PAHs for the organic solvent (cyclohexane) and to the different continuous extraction time at which the spiked sample is submitted (10 and $20 \mathrm{~min}$ ).

So it was established to perform the extraction of PAHs making a single treatment in ultrasound bath with cyclohexane. Then, aqueous/organic phases ratio has been investigated with the aim to increase the preconcentration factor.

Different volumes $(4,12$, and $20 \mathrm{~mL})$ of a tea infusion spiked with $5 \mathrm{ng}$ of each polycyclic aromatic hydrocarbon were treated with the same volume of extracting solvent $(4 \mathrm{~mL})$ for $20 \mathrm{~min}$. The results showed that the highest polycyclic aromatic hydrocarbons peak areas were obtained at $12 \mathrm{~mL}$ (preconcentration factor $=3$ ) while a $20-50 \%$ reduction occurred in the extraction recovery for all PAHs, with 


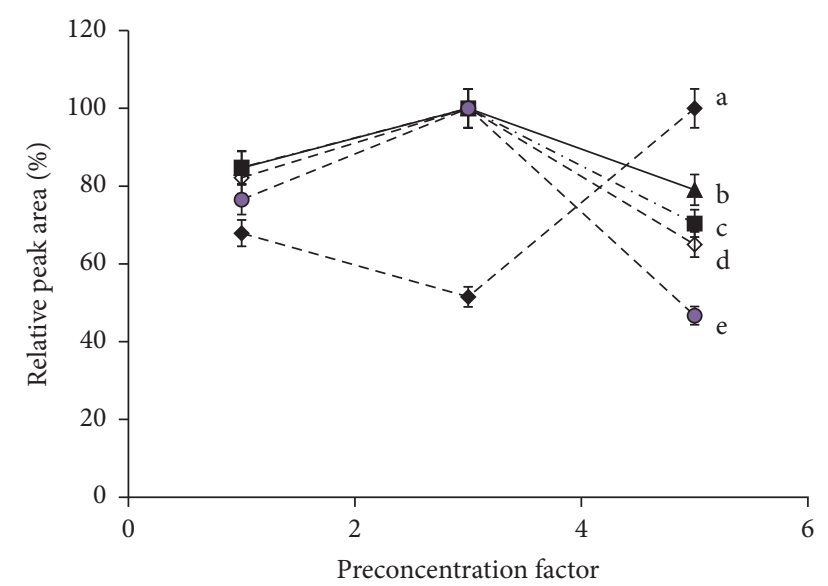

FIGURE 3: Effect of the preconcentration factor on some polycyclic aromatic hydrocarbons release from tea infusion to organic phase: a: indeno[1,2,3-cd]pyrene; b: benzo[a]pyrene; c: benzo[k]fluoranthene; $\mathrm{d}$ : benzo[b]fluoranthene; e: benzo[ghi]perylene.

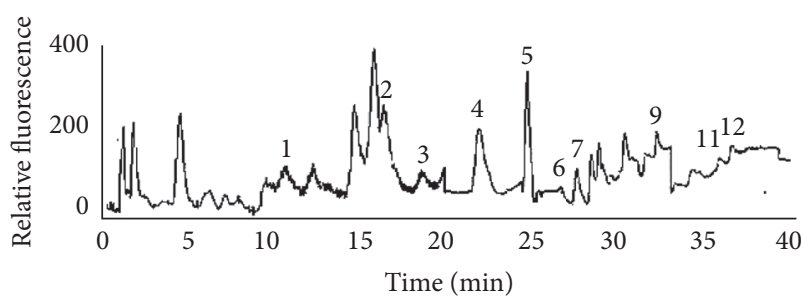

FIgURE 4: Chromatogram of a black tea sample: 1: naphthalene, 2: acenaphtene, 3: fluorene, 4: phenanthrene, 5: anthracene, 6: fluoranthene, 7: pyrene, 9: chrysene, 11: benzo[k]fluoranthene, and 12: benzo[a]pyrene. Chromatographic conditions as reported in Section 2.5.

the exception of indeno[1,2,3-cd]pyrene, when the sample volume reached $20 \mathrm{~mL}$ (preconcentration factor $=5$ ). For example, in Figure 3 behaviors of 5 PAHs are reported. Therefore, $12 \mathrm{~mL}$ of tea sample was chosen as the optimal value for further studies.

3.2. PAHs Determination after Saponification and LiquidLiquid Extraction Method. This method is based on the preliminary saponification of lipids in the tea infusion, even if these compounds are present in small amounts of $4.8 \%$ [4] and subsequently a liquid-liquid extraction with cyclohexane is performed, as reported in Section 2.5. In Figure 4 a black tea's chromatogram in which the contamination of 10 polycyclic aromatic hydrocarbons appears is instead reported.

\subsection{Percentage Recovery Comparison between Ultrasonic and} Liquid-Liquid Extraction Methods. In Table 1 the analytical parameters of chromatographic method are reported, like the retention time \pm standard deviation, linearity range with regression coefficient $\left(R^{2}\right)$ close to 0,99 , and the detection limit. Limit of detection (LOD), estimated on the signal of the background noise measured from the chromatograms of standard at the lowest calibration level, was calculated as three times higher than the level of noise. PAHs recoveries were carried out analyzing the same tea sample with both extraction methods by repeating the analysis for 5 times. The fortification was performed by adding 10 and $20 \mathrm{ng}$ of each $\mathrm{PAH}$ to $12 \mathrm{~mL}$ of tea infusion (equivalent to the concentration of $0.83 \mu \mathrm{g} / \mathrm{L}$ and $1.6 \mu \mathrm{g} / \mathrm{L}$, resp.) when ultrasonication method was employed. For the saponification-liquid-liquid extraction method, 1 and $2 \mathrm{ng}$ of polycyclic aromatic hydrocarbons were added to $4 \mathrm{~mL}$ of infusion (equivalent to the concentration of $0.25 \mu \mathrm{g} / \mathrm{L}$ and $0.5 \mu \mathrm{g} / \mathrm{L}$ ). Results, expressed as recovery\% $\pm \mathrm{SD}$ for each $\mathrm{PAH}$, with the exception of naphthalene, are reported in Table 2. Naphthalene which is fairly volatile was probably lost during the evaporation step under $\mathrm{N}_{2}$

Recoveries obtained with the sonication method are too low $(<70 \%)$ even if a small increase in the sample fortified with $1.6 \mu \mathrm{g} / \mathrm{L}$ of polycyclic aromatic hydrocarbons appears. The low recovery obtained can be probably due to an attenuation of ultrasonication intensity since the ultrasonic wave needs first to cross the liquid inside the bath and then to cross the wall of the sample container. This attenuation is obtained even if the base of the container employed is flat and the ultrasound reflected is a minimum [23].

In the method of saponification followed by liquidliquid extraction (LLE), the recoveries of all PAHs appear to be satisfactory (70-130\%) with the exception of acenaphthene and fluoranthene which present low recoveries $(<50 \%)$ when polycyclic aromatic hydrocarbons addition is $<2 \mathrm{ng}$. Indeno[1,2,3-cd]pyrene can be recovered only when its amount is higher than $2 \mathrm{ng}$.

Since the second method has been proved to be better than the first one, it has been chosen for polycyclic aromatic hydrocarbons determination in black tea samples taking into account each recovery value.

3.4. Determination of Polycyclic Aromatic Hydrocarbons in Tea Infusion Samples. The European Communities Regulation 835/2011 [5] fixed new limits in a range of foodstuffs taking into account both benzo[a]pyrene and the sum of 4 PAHs (benzo[a]pyrene, benz[a]anthracene, benzo[b]fluoranthene, and chrysene). However, some categories of food are not covered by this legislation, especially, dried food products like herbs and spices, and infusions like tea. In this last case, it might be more appropriate to refer to the polycyclic aromatic hydrocarbons limits set for drinking water. According to a European Union Directive (98/83/CE) [24], the maximum level allowed for benzo[a] pyrene is $10 \mathrm{ng} / \mathrm{L}$ and the maximum limit for the sum of benzo[k]fluoranthene, benzo[b]fluoranthene, benzo[g, $\mathrm{h}, \mathrm{i}]$ perylene, and indeno[1,2,3-cd]pyrene is $100 \mathrm{ng} / \mathrm{L}$. Given these parameters, three samples in this study exceeded the guideline value proposed for the sum of the 4 polycyclic aromatic hydrocarbons and two were higher than the limit value of benzo[a]pyrene (Table 3). The total mean polycyclic aromatic hydrocarbons content (sum of 15 polycyclic aromatic hydrocarbons) in tea samples ranged from 347 to $4120 \mathrm{ng} / \mathrm{L}$ and is higher than Polish tea infusions reported by Ciemniak and Mocek, [18] but lower than those reported by other authors [11, 14] for Asiatic black teas. When the 
TABLE 1: Analytical characteristics of chromatographic method.

\begin{tabular}{|c|c|c|c|c|c|}
\hline Peak & $\begin{array}{l}\text { Polycyclic aromatic } \\
\text { hydrocarbons }\end{array}$ & $\begin{array}{c}\text { Retention time } \\
(\text { min }) \pm \\
\text { standard deviation } \\
(\text { sample }=10)\end{array}$ & $\begin{array}{l}\text { Linearity range } \\
\text { (ng/L) }\end{array}$ & Regression coefficient & $\begin{array}{c}\text { Detection limit } \\
(\text { signal/noise }=3) \\
(\mathrm{ng} / \mathrm{L})\end{array}$ \\
\hline 1 & Naphthalene & $11.3 \pm 0.3$ & $2.1-500$ & 0.9998 & 0.63 \\
\hline 2 & Acenaphtene & $17.8 \pm 0.5$ & $5.3-300$ & 0.9998 & 1.60 \\
\hline 3 & Fluorene & $20.0 \pm 0.6$ & $5.0-30$ & 0.9509 & 1.50 \\
\hline 4 & Phenanthrene & $23.4 \pm 0.4$ & $1.7-40$ & 0.9963 & 0.35 \\
\hline 5 & Anthracene & $26.4 \pm 0.4$ & $0.66-20$ & 0.9999 & 0.20 \\
\hline 6 & Fluoranthene & $28.6 \pm 0.4$ & $4.2-15$ & 0.9930 & 1.25 \\
\hline 7 & Pyrene & $29.7 \pm 0.2$ & $7.0-100$ & 0.9984 & 2.10 \\
\hline 8 & Benz[a]anthracene & $33.4 \pm 0.9$ & $1.5-30$ & 0.9962 & 0.45 \\
\hline 9 & Chrysene & $34.9 \pm 0.3$ & $1.5-50$ & 0.9970 & 0.45 \\
\hline 10 & Benzo[b]fluoranthene & $37.4 \pm 0.3$ & $6.7-20$ & 0.9938 & 2.00 \\
\hline 11 & Benzo[k]fluoranthene & $38.9 \pm 0.1$ & $0.83-20$ & 0.9965 & 0.25 \\
\hline 12 & Benzo[a]pyrene & $39.5 \pm 0.3$ & $2.1-50$ & 0.9948 & 0.63 \\
\hline 13 & Dibenz $[\mathrm{a}, \mathrm{h}]$ anthracene & $41.1 \pm 0.3$ & $2.0-200$ & 0.9973 & 0.60 \\
\hline 14 & Benzo[ghi]perylene & $42.0 \pm 0.1$ & $4.6-80$ & 0.9969 & 1.40 \\
\hline 15 & Indeno $[1,2,3-c d]$ pyrene & $42.9 \pm 0.3$ & $33-50$ & 0.9944 & 10 \\
\hline
\end{tabular}

TABLE 2: Mean\% recoveries \pm standard deviation for added polycyclic aromatic hydrocarbons to black tea infusions obtained from liquidliquid extraction with shaking after saponification step and from ultrasonication in bath water.

\begin{tabular}{|c|c|c|c|c|}
\hline \multirow{4}{*}{ PAHs } & \multicolumn{4}{|c|}{ Mean recoveries \pm standard deviation } \\
\hline & \multicolumn{2}{|c|}{ Ultrasound extraction } & \multicolumn{2}{|c|}{ Liquid-liquid extraction } \\
\hline & $10 \mathrm{ng}$ & $20 \mathrm{ng}$ & $1 \mathrm{ng}$ & $2 \mathrm{ng}$ \\
\hline & $(0,83 \mathrm{ng} / \mathrm{mL})$ & $(1,6 \mathrm{ng} / \mathrm{mL})$ & $(0,25 \mathrm{ng} / \mathrm{mL})$ & $(0,50 \mathrm{ng} / \mathrm{mL})$ \\
\hline Acenaphtene & $40 \pm 3$ & $39 \pm 4$ & $40 \pm 29$ & $97 \pm 59$ \\
\hline Fluorene & $40 \pm 12$ & $48 \pm 2$ & $48 \pm 12$ & $62 \pm 10$ \\
\hline Phenanthrene & $70 \pm 3$ & $69 \pm 1$ & $103 \pm 6$ & $82 \pm 7$ \\
\hline Anthracene & $59 \pm 5$ & $56 \pm 1$ & $88 \pm 21$ & $89 \pm 16$ \\
\hline Fluoranthene & $53 \pm 3$ & $64 \pm 9$ & $88 \pm 22$ & $108 \pm 7$ \\
\hline Pyrene & $46 \pm 5$ & $64 \pm 7$ & $124 \pm 25$ & $129 \pm 23$ \\
\hline Benz[a]anthracene & $44 \pm 3$ & $58 \pm 2$ & $137 \pm 23$ & $119 \pm 18$ \\
\hline Chrysene & $45 \pm 4$ & $59 \pm 6$ & $128 \pm 24$ & $80 \pm 14$ \\
\hline Benzo[b]fluoranthene & $47 \pm 7$ & $63 \pm 6$ & $130 \pm 10$ & $105 \pm 10$ \\
\hline Benzo[k]fluoranthene & $45 \pm 4$ & $48 \pm 5$ & $109 \pm 16$ & $120 \pm 17$ \\
\hline Benzo[a]pyrene & $44 \pm 3$ & $53 \pm 5$ & $109 \pm 24$ & $95 \pm 20$ \\
\hline Dibenz[a,h]anthracene & $33 \pm 2$ & $41 \pm 4$ & $100 \pm 19$ & $87 \pm 16$ \\
\hline Benzo[ghi]perylene & $39 \pm 1$ & $66 \pm 9$ & $120 \pm 6$ & $70 \pm 6$ \\
\hline Indeno[1,2,3-cd]pyrene & $13 \pm 3$ & $52 \pm 9$ & - & $67 \pm 13$ \\
\hline
\end{tabular}

sum of benzo[a] anthracene, chrysene, benzo[b]fluoranthene, and benzo[a]pyrene is considered, the PAH content ranged between nondetectable values and $240 \mathrm{ng} / \mathrm{L}$ which are lower than the values reported by Pincemaille et. al [17].

The emerging variability is certainly due to the different contamination level of the tea for both different manufacturing process and different environmental PAHs exposure taking into account the different country provenience. In addition, difference in infusion procedure like tea weight/hot water ratios $(0,01-0,1 \mathrm{~g} / \mathrm{mL})$ and infusion times $(5-10 \mathrm{~min})$ can influence the results. Lin et al. [25] reported that the \% PAHs transferred to the infusion increase with the decrease of the above mentioned ratio and of the brewing time. Kamangar et al. [26] and Lin et al. [11] also agree with this last feature.

Figure 5 shows the distribution of polycyclic aromatic hydrocarbons in 10 samples of different brands. As can be seen, the PAHs less toxic with 3 rings are predominant in the infusions accounting for $63 \%$, while those with 4 rings contribute for $29 \%, 5$ rings for $7 \%$, and 6 rings only for $1 \%$. 
TABLE 3: Mean polycyclic aromatic hydrocarbons content of black tea infusion samples (ng/L) by saponification followed by liquid-liquid extraction.

\begin{tabular}{|c|c|c|c|c|c|c|c|c|c|c|}
\hline $\begin{array}{l}\text { Polycyclic aromatic } \\
\text { hydrocarbons }\end{array}$ & 1 & 2 & 3 & 4 & 5 & 6 & 7 & 8 & 9 & 10 \\
\hline Acenaphtene & $380 \pm 140$ & $1490 \pm 20$ & $110 \pm 80$ & $120 \pm 40$ & $70 \pm 40$ & - & - & - & - & - \\
\hline Fluorene & $170 \pm 50$ & $250 \pm 20$ & $40 \pm 18$ & $30 \pm 10$ & $40 \pm 15$ & $50 \pm 30$ & $317 \pm 60$ & $204 \pm 50$ & $290 \pm 45$ & $272 \pm 35$ \\
\hline Phenanthrene & $710 \pm 30$ & $1250 \pm 80$ & $120 \pm 20$ & $800 \pm 110$ & $\begin{array}{c}1220 \pm \\
220\end{array}$ & $280 \pm 80$ & $377 \pm 15$ & $80 \pm 10$ & $1049 \pm 22$ & $40 \pm 10$ \\
\hline Anthracene & $70 \pm 6$ & $190 \pm 10$ & $30 \pm 3$ & $90 \pm 18$ & $170 \pm 40$ & $20 \pm 5$ & - & $190 \pm 23$ & - & - \\
\hline Fluoranthene & $200 \pm 30$ & $630 \pm 30$ & $90 \pm 22$ & $110 \pm 10$ & $670 \pm 90$ & $140 \pm 20$ & - & - & $1276 \pm 143$ & - \\
\hline Pyrene & $110 \pm 10$ & $310 \pm 10$ & $100 \pm 15$ & $100 \pm 10$ & $370 \pm 50$ & $80 \pm 10$ & - & $70 \pm 10$ & - & - \\
\hline Benz[a]anthracene & - & $70 \pm 10$ & - & - & - & - & $21 \pm 5$ & - & - & - \\
\hline Chrysene & $20 \pm 3$ & $100 \pm 10$ & $130 \pm 40$ & - & $35 \pm 8$ & $30 \pm 6$ & - & - & - & $22 \pm 5$ \\
\hline Benzo[b]fluoranthene & $50 \pm 10$ & $30 \pm 1$ & - & - & $110 \pm 20$ & - & $150 \pm 22$ & - & - & $13 \pm 3$ \\
\hline Benzo $[\mathrm{k}]$ fluoranthene & - & $20 \pm 6$ & $10 \pm 4$ & - & $40 \pm 10$ & - & - & - & - & - \\
\hline Benzo[a]pyrene & - & $40 \pm 9$ & $20 \pm 6$ & - & - & - & - & - & - & - \\
\hline Dibenz $[\mathrm{a}, \mathrm{h}]$ anthracene & - & - & - & - & - & - & - & - & - & - \\
\hline Benzo[ghi]perylene & $80 \pm 10$ & - & - & - & - & - & - & - & - & - \\
\hline $\begin{array}{l}\text { Indeno[1,2,3- } \\
\text { cd]pyrene }\end{array}$ & $50 \pm 10$ & $40 \pm 10$ & - & - & - & - & - & - & - & - \\
\hline $\begin{array}{l}\text { Sum of } \\
\text { benzo[b]fluoranthene, } \\
\text { benzo[k]fluoranthene, } \\
\text { benzo[ghi]perylene, } \\
\text { and indeno[1,2,3- } \\
\text { cd]pyrene }\end{array}$ & $180 \pm 17$ & $90 \pm 15$ & $10 \pm 7$ & - & $150 \pm 22$ & - & $150 \pm 22$ & - & - & - \\
\hline $\begin{array}{l}\text { Sum of all polycyclic } \\
\text { aromatic } \\
\text { hydrocarbons }\end{array}$ & $2310 \pm 155$ & $4120 \pm 92$ & $680 \pm 99$ & $1940 \pm 120$ & $\begin{array}{c}3030 \pm \\
251\end{array}$ & $600 \pm 89$ & $865 \pm 66$ & $544 \pm 52$ & $2615 \pm 151$ & $347 \pm 37$ \\
\hline
\end{tabular}

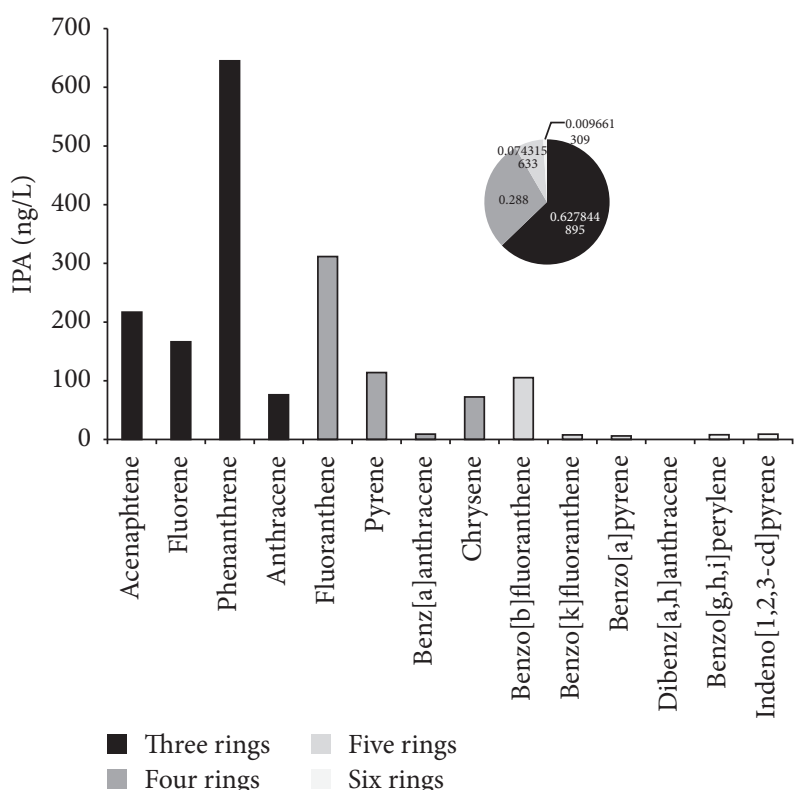

Figure 5: Distribution of polycyclic aromatic hydrocarbons in 10 Italian commercial black tea infusions.

This is in accordance with the different aqueous solubility [27] and octanol-water partition coefficient $\left(\log K_{\text {ow }}\right)$ [28]. Indeed, increasing the number of rings, PAHs solubility decreases while $\log K_{\text {ow }}$ rises. This is in accordance with results reported by Lin et al. [11] which argued that the percentages of PAHs released from the tea into the liquor were inversely proportional to the $\log K_{\text {ow }}$.

\section{Conclusion}

A sensitive HPLC-FLD method was employed for PAHs occurrence in 10 samples of tea purchased in the main Italian supermarkets. The liquid-liquid extraction of polycyclic aromatic hydrocarbons with cyclohexane, after a saponification step, was preferred to ultrasonic extraction since better recoveries were obtained (70-130\%). The \% relative standard deviation (RSD) for the whole method was in the range $5-25 \%$. Contamination of black tea infusion, expressed as sum of 4 polycyclic aromatic hydrocarbons (benzo[k]fluoranthene, benzo[b]fluoranthene, benzo[g,h,i]perylene, and indeno[1,2,3-cd]pyrene) or total analyzed PAHs, was significantly lower than that reported for Chinese and Indian tea. It was noted that concentrations of five samples were above the limits established by the European Community for drinking waters.

\section{Competing Interests}

All the authors declare that there is no conflict of interests regarding the publication of this paper. 


\section{References}

[1] Y.-C. Yang, F.-H. Lu, J.-S. Wu, C.-H. Wu, and C.-J. Chang, “The protective effect of habitual tea consumption on hypertension," Archives of Internal Medicine, vol. 164, no. 14, pp. 1534-1540, 2004.

[2] S. K. Katiyar and K. Mukhtar, "Tea in chemoprevention of cancer: epidemiologic and experimental studies," International Journal of Oncology, vol. 8, no. 2, pp. 221-238, 1996.

[3] P. M. Kris-Etherton, K. D. Hecker, A. Bonanome et al., "Bioactive compounds in foods: their role in the prevention of cardiovascular disease and cancer," The American Journal of Medicine, vol. 113, no. 9, supplement 2, pp. 71-88, 2002.

[4] International Agency for Research on Cancer (IARC), Monographs on the Evaluation of the Carcinogenic Risk of Chemicals to Humans, Overall Evaluation of Carcinogenity: An Updating of IARC Monographs, vol. 1-42, supplement 7, International Agency for Research on Cancer, Lyon, France, 1987.

[5] Council of the European Union, "Commission Regulation (EU) No 835/2011 (19 August 2011) Amending Regulation (EC) No $1881 / 2006$ as regards maximum levels for polycyclic aromatic hydrocarbons in foodstuffs," Official Journal of the European Union, vol. L 215/4, 2011.

[6] K. Ziegenhals, W. Jira, and K. Speer, "Polycyclic aromatic hydrocarbons (PAH) in various types of tea," European Food Research and Technology, vol. 228, no. 1, pp. 83-91, 2008.

[7] D. Lin and L. Zhu, "Polycyclic aromatic hydrocarbons: pollution and source analysis of a black tea," Journal of Agricultural and Food Chemistry, vol. 52, no. 26, pp. 8268-8271, 2004.

[8] US and EPA, Polycyclic Organic Matter, Environmental Protection Agency, Washington, DC, USA, 2002, http://www.epa.gov/ ttn/atw/hlthef/polycycl.html.

[9] H. Fiedler, C. K. Cheung, and M. H. Wong, "PCDD/PCDF, chlorinated pesticides and PAH in Chinese teas," Chemosphere, vol. 46, no. 9-10, pp. 1429-1433, 2002.

[10] M. Khiadani, M. Mehdi Amin, F. Momen Beik, A. Ebrahimi, M. Farhadkhani, and F. Mohammadi-Moghadam, "Determination of polycyclic aromatic hydrocarbons concentration in eight brands of black tea which are used more in Iran," International Journal of Environmental Health Engineering, vol. 2, article 40, 2013.

[11] D. Lin, Y. Tu, and L. Zhu, "Concentrations and health risk of polycyclic aromatic hydrocarbons in tea," Food and Chemical Toxicology, vol. 43, no. 1, pp. 41-48, 2005.

[12] G. V. A. Londoño, C. M. Reynoso, and S. L. Resnik, "Polycyclic aromatic hydrocarbons (PAHs) survey on tea (Camellia sinensis) commercialized in Argentina," Food Control, vol. 50, pp. 3137, 2015.

[13] A. Afolabi, J. Angelica, W. Cara, C. Kevin, N. Thao, and A. S. Mahmoud, "Determination of polycyclic aromatic hydrocarbons in dry tea," Journal of Environmental Science and Health, Part B, vol. 50, pp. 552-559, 2015.

[14] L. Drabova, J. Pulkrabova, K. Kalachova, M. Tomaniova, V. Kocourek, and J. Hajslova, "Rapid determination of polycyclic aromatic hydrocarbons (PAHs) in tea using two-dimensional gas chromatography coupled with time of flight mass spectrometry," Talanta, vol. 100, pp. 207-216, 2012.

[15] M. N. Kayali-Sayadi, "Rapid determination of polycyclic aromatic hydrocarbons in tea infusion samples by highperformance liquid chromatography and fluorimetric detection based on solid-phase extraction," Analyst, vol. 123, no. 10, pp. 2145-2148, 1998.
[16] N. R. Bishnoi, U. Mehta, U. Sain, and G. G. Pandit, "Quantification of polycyclic aromatic hydrocarbons in tea and coffee samples of Mumbai City (India) by high performance liquid chromatography," Environmental Monitoring and Assessment, vol. 107, no. 1-3, pp. 399-406, 2005.

[17] J. Pincemaille, C. Schummer, E. Heinen, and G. Moris, "Determination of polycyclic aromatic hydrocarbons in smoked and non-smoked black teas and tea infusions," Food Chemistry, vol. 145, pp. 807-813, 2014.

[18] A. Ciemniak and K. Mocek, "Polycyclic aromatic hydrocarbons in tea and tea infusions," Roczniki Państwowego Zakładu Higieny, vol. 61, no. 3, pp. 243-248, 2010.

[19] N. E. Díaz-Moroles, H. J. Garza-Ulloa, R. Castro-Ríos et al., "Comparison of the performance of two chromatographic and three extraction techniques for the analysis of PAHs in sources of drinking water," Journal of Chromatographic Science, vol. 45, no. 2, pp. 57-62, 2007.

[20] A. Filipkowska, L. Lubecki, and G. Kowalewska, "Polycyclic aromatic hydrocarbon analysis in different matrices of the marine environment," Analytica Chimica Acta, vol. 547, no. 2, pp. 243-254, 2005.

[21] A. M. Girelli, D. Sperati, and A. M. Tarola, "Determination of polycyclic aromatic hydrocarbons in Italian milk by HPLC with fluorescence detection," Food Additives and Contaminants Part $A$, vol. 31, no. 4, pp. 703-710, 2014.

[22] H. R. Falleh, M. Ksouri, E. Lucchessi, C. Abdelly, and C. Magné, "Ultrasound-assisted extraction: effect of extraction time and solvent power on the levels of polyphenols and antioxidant activity of Mesembryanthemum edule L. Aizoaceae shoots," Tropical Journal of Pharmaceutical Research, vol. 11, pp. 243-249, 2012.

[23] J. L. Capelo Martinez, Ultrasound in Chemistry: Analytical Application, Wiley VCH Verlag GmbH \& Co, KGA, Weinheim, Germany, 2009.

[24] The Council of the European Union, "Council Directive 98/83/EC of 3 November 1998 on the quality of water intended for human consumption," Official Journal of the European Communities, vol. 1, no. 330-332, 1998.

[25] D. Lin, L. Zhu, and L. Luo, "Factors affecting transfer of polycyclic aromatic hydrocarbons from made tea to tea infusion," Journal of Agricultural and Food Chemistry, vol. 54, no. 12, pp. 4350-4354, 2006.

[26] F. Kamangar, M. M. Schantz, C. C. Abnet, R. B. Fagundes, and S. M. Dawsey, "High levels of carcinogenic polycyclic aromatic hydrocarbons in mate drinks," Cancer Epidemiology Biomarkers and Prevention, vol. 17, no. 5, pp. 1262-1268, 2008.

[27] G.-N. Lu, Z. Dang, X.-Q. Tao, C. Yang, and X.-Y. Yi, "Estimation of water solubility of polycyclic aromatic hydrocarbons using quantum chemical descriptors and partial least squares," QSAR and Combinatorial Science, vol. 27, no. 5, pp. 618-626, 2008.

[28] D. Mackay and K. E. Clark, "Predicting the environmental partitioning of organic contaminants and their transfer to biota," in Organic Contaminants in the Environment: Environmental Pathways \& Effects, K. C. Jones, Ed., vol. 19 of Environmental Management Series, pp. 159-188, Elsevier Applied Science Pubblishers, New York, NY, USA, 1991. 

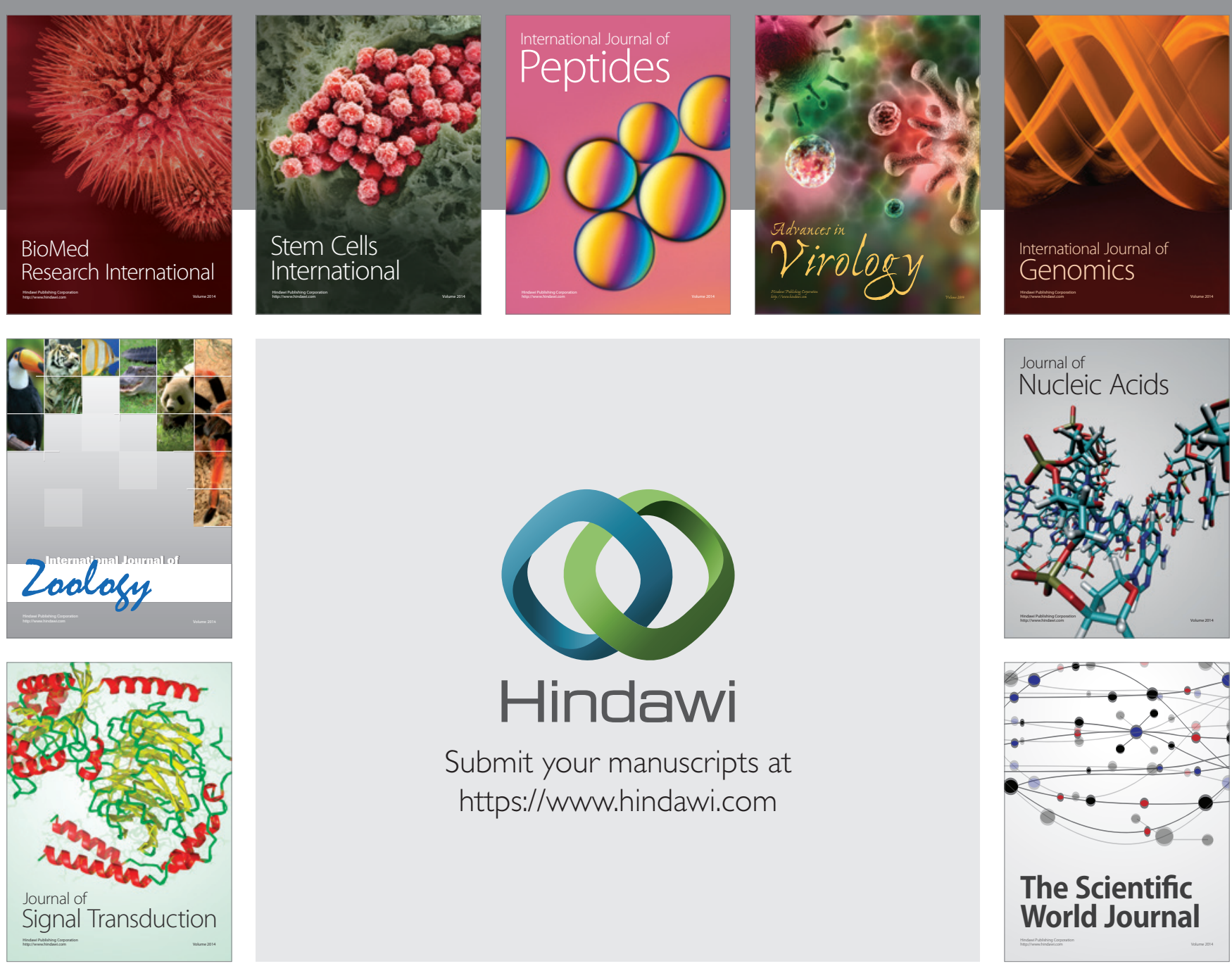

Submit your manuscripts at

https://www.hindawi.com
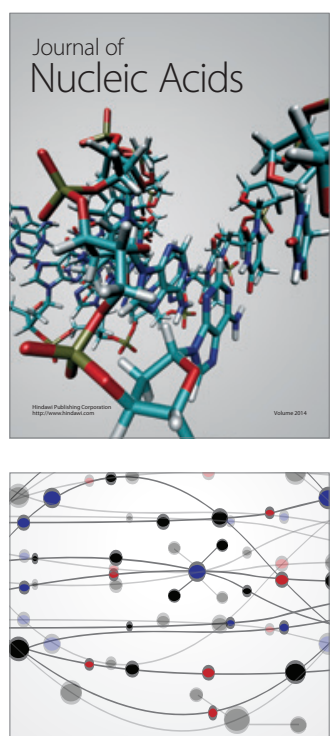

The Scientific World Journal
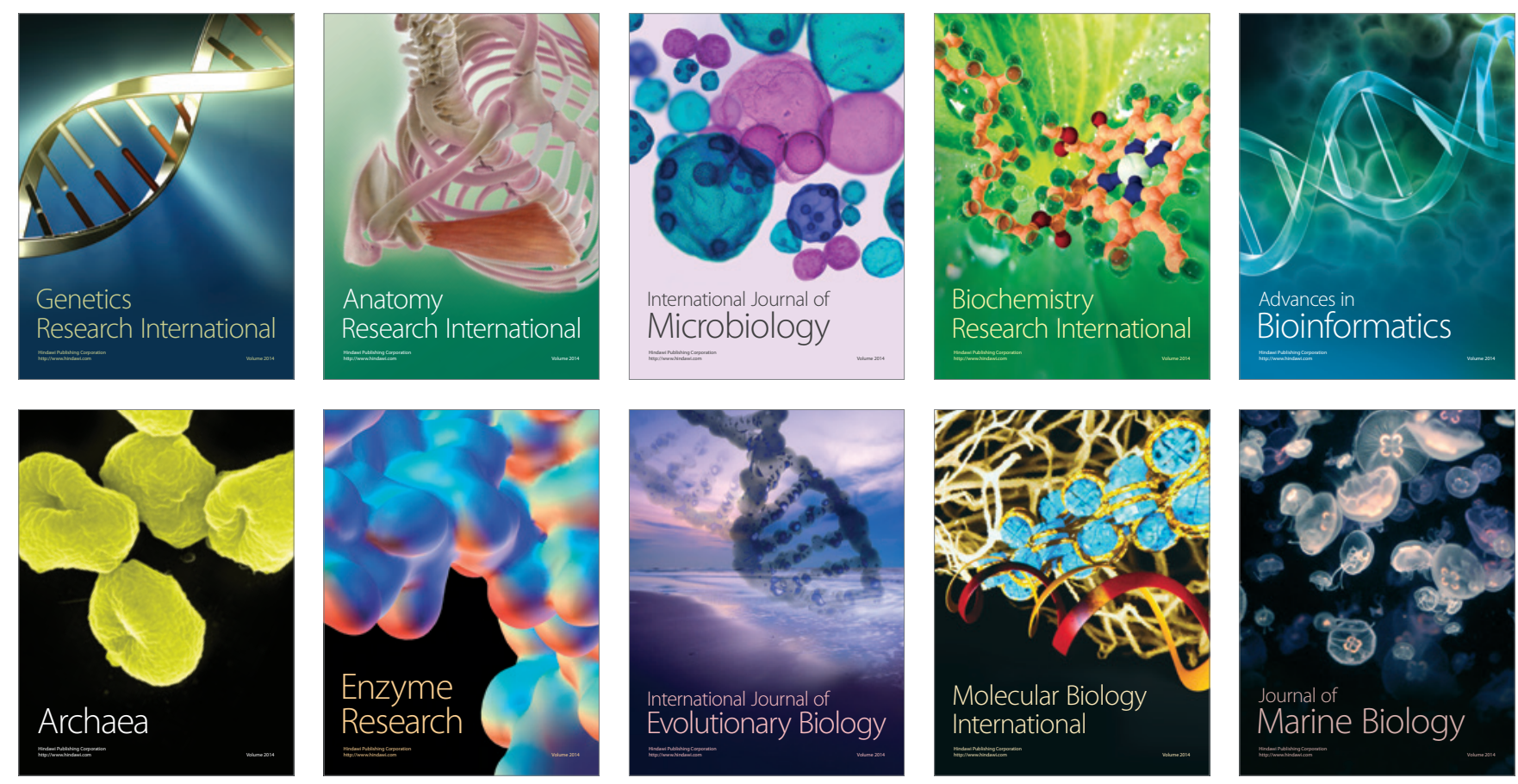